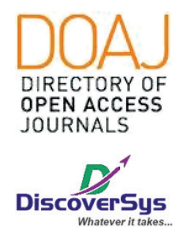

Published by DiscoverSys

\section{Penilaian mutu asuhan keperawatan sebelum dan sesudah penerapan clinical pathway di Rumah Sakit Umum Pusat (RSUP) Sanglah, Bali, Indonesia}

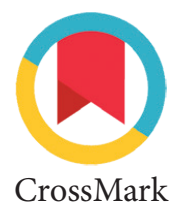

\author{
I Made Artana, ${ }^{1 *}$ Putu Ayu Indrayathi, ${ }^{1,2}$ | Made Ady Wirawan ${ }^{1,2}$
}

\title{
ABSTRACT
}

Background: Hospitals implement clinical pathways in an effort to improve the quality of health services, especially the quality of nursing care. This study aims to determine whether the quality of nursing care after the application of the clinical pathway is better than the quality of nursing care prior to the clinical pathway application.

Methods: This study used 180 inpatient medical records in January 2017May 2019 with five priority medical diagnoses namely cerebral concussion and epidural hematoma (conservative therapy), conservative treatment of preterm premature rupture of membranes, ablation of atrioventricular nodal reentrant tachycardia (AVNRT), atrioventricular reentrant tachycardia (AVRT), atrial tachycardia, atrial fibrillation, premature ventricular contractions (PVC), ventricular tachycardia (VT), junctional tachycardia and intracerebral haemorrhage (hemorrhagic stroke) as well as post-Lapastomy frozen section in the selected cystic ovary with a selective curative cyst. The variables studied were the application of clinical pathway, quality of nursing care, quality of assessment, diagnosis, planning, implementation and evaluation of nursing. Data were analyzed with the Pearson Chi-Square Test on SPSS version 17 for Windows.
Results: The quality of good nursing care before and after the application of clinical pathway was $15.2 \%$ versus $50.9 \%(p=0.00)$; good quality of nursing assessment before and after clinical pathway application of $6.7 \%$ versus $64.9 \%(p=0.00)$; good quality of diagnosis before and after clinical pathway application of $72.7 \%$ versus $73.7 \%$ ( $p=0.889$ ); the quality of the nursing plan which consisted of good quality of goal formulation before and after the application of clinical pathway was $75.8 \%$ versus $73.7 \%(p=0.759)$; good quality determination of interventions before and after clinical pathway application of $75.8 \%$ versus $79.8 \%(p=0.523)$, good quality of implementation before and after clinical pathway application of $100 \%$ versus $100 \%$ and good quality of nursing evaluation before and after the application of clinical pathway is $100 \%$ versus $100 \%$.

Conclusion: The quality of nursing care and nursing assessment after the implementation of clinical pathway is significantly better than before the implementation of clinical pathway, while no significant difference was found in the quality of diagnosis, planning, implementation and evaluation of nursing.

Keywords: Clinical Pathway, Inpatients, Quality of Nursing Care

Cite This Article: Artana, I.M., Indrayathi, P.A., Wirawan, I.M.A. 2020. Penilaian mutu asuhan keperawatan sebelum dan sesudah penerapan clinical pathway di Rumah Sakit Umum Pusat (RSUP) Sanglah, Bali, Indonesia. Intisari Sains Medis 11(2): 528-534. D0I: 10.15562/ism.v11i2.655

\section{ABSTRAK}

'Program Studi Magister IImu Kesehatan Masyarakat, Fakultas Kedokteran, Universitas Udayana, Bali, Indonesia

${ }^{2}$ Departemen Kesehatan Masyarakat dan Kedokteran Pencegahan, Fakultas Kedokteran, Universitas Udayana, Bali, Indonesia

*Korespondensi: I Made Artana, Program Studi Magister IImu Kesehatan Masyarakat, Fakultas Kedokteran, Universitas Udayana, Bali, Indonesia madeartana82@yahoo.com

Diterima: 31-10-2019

Disetujui: 09-07-2020

Diterbitkan: 11-07-2020
Latar Belakang: Rumah sakit menerapkan clinical pathway dalam upaya meningkatkan mutu pelayanan kesehatan khususnya mutu asuhan keperawatan. Penelitian ini bertujuan untuk mengetahui apakah mutu asuhan keperawatan sesudah penerapan clinical pathway lebih baik daripada mutu asuhan keperawatan sebelum penerapan clinical pathway.

Metode: Penelitian ini menggunakan 180 rekam medis pasien rawat inap pada bulan Januari 2017-Mei 2019 dengan lima diagnosis medis prioritas yaitu cerebral concussion dan epidural hematoma (terapi konservatif), penanganan konservatif ketuban pecah dini preterm, ablasi pada atrioventricular nodal reentrant tachycardia (AVNRT), atrioventricular reentrant tachycardia (AVRT), atrial takikardi, atrial fibrilasi, premature ventricular contractions (PVC), ventricular tachycardia (VT), junctional takikardi dan intracerebral haemorrhage (stroke hemoragik) serta post laparatomi frozen section pada kista ovarii curiga ganasyang dipilih dengan purposivesampling. Variabelyang ditelitiadalah penerapan clinical pathway, mutu asuhan keperawatan, mutu pengkajian, penegakan diagnosis, rencana, implementasi dan evaluasi keperawatan. Data dianalisis dengan Uji Pearson Chi-Square pada SPSS versi 17 untuk Windows.
Hasil: Mutu asuhan keperawatan yang baik sebelum dan sesudah penerapan clinical pathway sebesar $15,2 \%$ versus $50,9 \%(p=0,00)$; mutu pengkajian keperawatan yang baik sebelum dan sesudah penerapan clinical pathway sebesar $6,7 \%$ versus $64,9 \%(p=0,00)$; mutu penegakan diagnosis yang baik sebelum dan sesudah penerapan clinical pathway sebesar $72,7 \%$ versus $73,7 \%(p=0,889)$; mutu rencana keperawatan yang terdiri mutu perumusan tujuan yang baik sebelum dan sesudah penerapan clinical pathway sebesar $75,8 \%$ versus $73,7 \%$ $(p=0,759)$; mutu penentuan intervensi yang baik sebelum dan sesudah penerapan clinical pathway sebesar $75,8 \%$ versus $79,8 \%(p=0.523)$, mutu implementasi yang baik sebelum dan sesudah penerapan clinical pathway sebesar $100 \%$ versus $100 \%$ dan mutu evaluasi keperawatan yang baik sebelum dan sesudah penerapan clinical pathway sebesar $100 \%$ versus $100 \%$.

Simpulan: Mutu asuhan keperawatan dan pengkajian keperawatan sesudah penerapan clinical pathway secara signifikan lebih baik daripada sebelum penerapan clinical pathway, sedangkan mutu penegakan diagnosis, rencana, implementasi dan evaluasi keperawatan tidak terdapat perbedaan yang signifikan. 
Kata Kunci: Clinical Pathway, Pasien Rawat Inap, Mutu Asuhan Keperawatan

Cite Pasal Ini: Artana, I.M., Indrayathi, P.A., Wirawan, I.M.A. 2020. Penilaian mutu asuhan keperawatan sebelum dan sesudah penerapan clinical pathway di Rumah Sakit Umum Pusat (RSUP) Sanglah, Bali, Indonesia. Intisari Sains Medis 11(2): 528-534. D0I: 10.15562/ism.v11i2.655

\section{PENDAHULUAN}

Kualitas pelayanan kesehatan adalah suatu kondisi dimana layanan kesehatan untuk individu maupun masyarakat dapat meningkatkan kemungkinan pencapaian hasil kesehatan yang optimal serta sesuai dengan perkembangan pengetahuan profesional terkini yang diselenggarakan secara efektif, efisien, aman, berpusat pada pasien, tepat waktu, merata, serta terintegrasi. ${ }^{1,2}$ Kualitas layanan kesehatan pada negara berpenghasilan rendah dan menengah menunjukkan variasi yang signifikan didalam ketidakhadiran petugas kesehatan, produktivitas dalam pelayanan, akurasi dalam menegakkan diagnosis, dan kepatuhan terhadap pedoman pelayanan klinis. ${ }^{3}$ Data dari negara-negara berpenghasilan tinggi menunjukkan wanita berusia 50-69 tahun belum seluruhnya mendapatkan skrining mamografi, penduduk yang berusia 65 tahun ke atas belum seluruhnya menerima vaksinasi influenza, terjadi infeksi silang, variasi dalam pelayanan kesehatan yang tidak beralasan, alur pelayanan kesehatan terlalu rumit dan tidak dikoordinasikan dengan baik. ${ }^{3}$ Kualitas pelayanan kesehatan yang tidak sesuai standar tersebut menimbulkan berbagai masalah kesehatan yaitu ibu dan bayi baru lahir meninggal dikarenakan layanan persalinan di fasilitas pelayanan kesehatan yang tidak adekuat, pemicu utama kematian berlebihan, terjadinya resistensi antimikroba serta peningkatan pengeluaran biaya untuk untuk merawat pasien dengan komplikasi dari perawatan dan perawatan akibat kesalahan pengobatan. ${ }^{3,4}$

Para pemangku kepentingan, penyedia layanan kesehatan, manajer serta pengambil kebijakan di bidang kesehatan telah melakukan berbagai upaya untuk meningkatkan kualitas pelayanan kesehatan, salah satunya dengan menetapkan standar praktik klinik berupa clinical pathway., Clinical pathway merupakan rencana perawatan multidisiplin berbasis bukti yang terstruktur dan terintegrasi untuk memberikan panduan penatalaksanaan hari perhari dalam perawatan pasien dengan kondisi kesehatan tertentu guna mengatur dan menstandarisasi perawatan klinis pasien secara efektif dan efisien. ${ }^{7}$ Penerapan clinical pathway memiliki efek positif terhadap peningkatan kualitas pelayanan kesehatan, meningkatkan kepuasan pasien, mengurangi variasi dalam perawatan klinis, mengurangi morbiditas dan mortalitas serta menjembatani kesenjangan antara praktik klinis dan perawatan berbasis bukti. ${ }^{78}$ Perawat sebagai salah satu profesional pemberi asuhan, ikut serta dalam menyusun clinical pathway dengan pendekatan proses asuhan keperawatan yang terdiri dari tahap pengkajian, penegakan diagnosis, perencanaan, implementasi serta evaluasi keperawatan.

Rumah Sakit Umum Pusat (RSUP) Sanglah Denpasar sebagai fasilitas kesehatan rujukan tipe A pendidikan juga menetapkan clinical pathway sebagai acuan dalam memberikan pelayanan kesehatan sejak tahun 2013 dan pada tahun 2018 Direktur Utama RSUP Sanglah Denpasar menetapkan lima area klinis prioritas yaitu clinical pathway cerebral concussion dan epidural hematoma (terapi konservatif), penanganan konservatif ketuban pecah dini preterm, ablasi pada atrioventricular nodal reentrant tachycardia (AVNRT), atrioventricular reentrant tachycardia (AVRT), atrial takikardi, atrial fibrilasi, premature ventricular contractions (PVC), ventricular tachycardia (VT), junctional takikardi dan intracerebral haemorrhage (stroke hemoragik) serta post laparatomi frozen section pada kista ovarii curiga ganas. ${ }^{9,10}$ Evaluasi terhadap penerapan clinical pathway tersebut dengan menggunakan indikator medis mendapatkan tingkat kepatuhan 92,5\% sedangkan evaluasi penerapan clinical pathway terhadap mutu asuhan keperawatan dengan mengggunakan indikator proses asuhan keperawatan belum pernah dilaksanakan. ${ }^{11}$ Hasil pencarian tinjauan pustaka yang dilaksanakan oleh penulis, belum menemukan adanya penelitian yang dipublikasikan mengenai mutu asuhan keperawatan sebelum dan sesudah penerapan clinical pathway di rumah sakit. Berdasarkan hal tersebut, penelitian ini bertujuan untuk mengetahui apakah mutu asuhan keperawatan sesudah penerapan clinical pathway lebih baik daripada sebelum penerapan clinical pathway.

\section{METODE}

Penelitian ini menggunakan data sekunder dari rekam medis pasien rawat inap dengan lima diagnosis medis prioritas penerapan clinical pathway yang dipilih dengan tehnik purposive sampling. Mutu asuhan keperawatan sebelum penerapan clinical pathway menggunakan rekam medis tahun 2017 sejumlah 66 rekam medis dan sesudah penerapan clinical pathway menggunakan rekam medis tahun 2018 sampai bulan Mei 2019 sejumlah 114 rekam medis. Mutu asuhan keperawatan yang dinilai adalah mutu asuhan keperawatan secara umum dan mutu asuhan secara khusus yang terdiri dari mutu pengkajian, diagnosis, rencana, implementasi dan evaluasi keperawatan. Instrumen yang 
digunakan adalah ceklis observasi. Penilaian mutu asuhan dilaksanakan dengan membandingkan pelaksanaan asuhan keperawatan yang didokumentasikan dalam rekam medis pasien dengan panduan asuhan keperawatan dan clinical pathway yang sudah ditetapkan di RSUP Sanglah Denpasar. Penulis memberi skor 2 untuk indikator yang sesuai dengan standar, skor 1 untuk indikator yang tidak sesuai standar namun dengan variasi yang relevan dan skor 0 untuk indikator yang tidak sesuai standar. Data skor tersebut dikategorikan sebagai mutu asuhan keperawatan yang baik dengan skor 2 dan 1 serta mutu asuhan kurang dengan skor 0 .

Seluruh data yang telah diperoleh kemudian dianalisis dengan piranti lunak SPSS versi 17 untuk Windows dimana ditampilkan dalam bentuk persentase, jumlah absolut, maupun nilai kebermaknaan secaar statistik yang diuji dengan Pearson Chi Square.

\section{HASIL}

Hasil analisis karakteristik pasien berdasarkan sosio demografi dan variabel lainnya menunjukkan proporsi pasien terbanyak pada usia 60-69 tahun

Tabel 1 Mutu Asuhan Keperawatan

\begin{tabular}{|c|c|c|}
\hline Mutu Asuhan Keperawatan & $\mathrm{N}=180$ & $\%$ \\
\hline \multicolumn{3}{|l|}{ Pengkajian } \\
\hline Kurang & 95 & 52,8 \\
\hline Baik & 85 & 47,2 \\
\hline \multicolumn{3}{|l|}{ Pengkajian Lanjutan } \\
\hline Kurang & 0 & 0 \\
\hline Baik & 180 & 100,0 \\
\hline \multicolumn{3}{|l|}{ Diagnosis } \\
\hline Kurang & 48 & 26,7 \\
\hline Baik & 132 & 73,3 \\
\hline \multicolumn{3}{|l|}{ Tujuan } \\
\hline Kurang & 46 & 25,6 \\
\hline Baik & 134 & 74,4 \\
\hline \multicolumn{3}{|l|}{ Intervensi } \\
\hline Kurang & 39 & 21,7 \\
\hline Baik & 141 & 78,3 \\
\hline \multicolumn{3}{|l|}{ Implementasi } \\
\hline Kurang & 0 & 0 \\
\hline Baik & 180 & 100,0 \\
\hline \multicolumn{3}{|l|}{ Evaluasi Formatif } \\
\hline Kurang & 0 & 0 \\
\hline Baik & 180 & 100,0 \\
\hline \multicolumn{3}{|l|}{ Evaluasi Sumatif } \\
\hline Kurang & 0 & 0 \\
\hline Baik & 180 & 100,0 \\
\hline
\end{tabular}

$(27,8 \%)$, jenis kelamin perempuan $(67,8 \%)$, tingkat pendidikan sekolah menengah atas (42,2\%), tidak bekerja (35\%), status pembayaran JKN BPJS KIS (53, 9\%), diagnosis medis post laparatomi frozen section pada kista ovarii curiga ganas $(34,4 \%)$, menggunakan clinical pathway (63,3\%), jumlah hari rawat inap 1-5 hari $(51,7 \%)$ dan perawat sebagai pemberi asuhan keperawatan (57,8\%) (Tabel 1).

Tabel 1 menunjukkan proporsi mutu asuhan keperawatan yang terbanyak adalah mutu pengkajian keperawatan yang terdiri dari pengkajian awal yang kurang $(52,8 \%)$ dan pengkajian lanjutan yang baik (100\%). Di samping itu, mutu penegakan diagnosis keperawatan sebagian besar dikatakan baik (73,3\%), diikuti dengan mutu rencana keperawatan yang terdiri dari perumusan tujuan yang baik (74,4\%), penentuan intervensi yang baik $(78,3 \%)$, mutu implementasi keperawatan baik (100\%), mutu evaluasi keperawatan yang terdiri dari evaluasi formatif yang baik (100\%) dan evaluasi sumatif yang baik (100\%) (Tabel 1).

Tabel 2 menyajikan data proporsi mutu asuhan keperawatan yang baik sebelum dan sesudah penerapan clinical pathway sebesar $15,2 \%$ versus $50,9 \%(\mathrm{p}=0,00)$ dimana nilai $\mathrm{p}<0,05$ yang berarti terdapat perbedaan mutu asuhan keperawatan yang signifikan, dimana mutu asuhan keperawatan sesudah penerapan clinical pathway lebih baik daripada sebelum penerapan clinical pathway.

Hasil analisis perbedaan mutu pengkajian keperawatan menunjukkan proporsi mutu pengkajian keperawatan yang baik sebelum dan sesudah penerapan clinical pathway sebesar $16,7 \%$ versus $64,9 \%(\mathrm{p}=0,00)$ dimana nilai $\mathrm{p}<0,05$ yang berarti terdapat perbedaan mutu pengkajian keperawatan yang signifikan dimana mutu pengkajian keperawatan sesudah penerapan clinical pathway lebih baik daripada mutu pengkajian keperawatan sebelum penerapan clinical pathway. Proporsi mutu pengkajian keperawatan lanjutan sebelum dan sesudah penerapan clinical pathway dengan mutu yang baik sebesar $100 \%$, uji beda tidak dapat dilaksanakan oleh karena data tidak bervariasi.

Tabel 2 menunjukkan perbedaan proporsi mutu asuhan keperawatan sebelum dan sesudah penerapan clinical pathway. Perbedaan mutu penegakan diagnosis keperawatan menunjukkan proporsi mutu penegakan diagnosis keperawatan yang baik sebelum dan sesudah penerapan clinical pathway sebesar $72,7 \%$ versus $73,7 \%(p=0,889)$. Analisa perbedaan mutu rencana keperawatan terdiri dari mutu perumusan tujuan keperawatan dan penentuan intervensi keperawatan. Tabel 2 menunjukkan proporsi mutu perumusan tujuan keperawatan yang baik sebelum dan sesudah penerapan clinical pathway sebesar $75,8 \%$ versus $73,7 \%(p=0,759)$ serta proporsi mutu penentuan intervensi keperawatan 
Tabel 2 Perbedaan Mutu Asuhan Keperawatan Sebelum dan Sesudah Penerapan Clinical Pathway

\begin{tabular}{|c|c|c|c|}
\hline Mutu Asuhan Keperawatan & $\begin{array}{c}\text { Sebelum } \\
(\mathrm{N}=66)\end{array}$ & $\begin{array}{l}\text { Sesudah } \\
(N=114)\end{array}$ & $\mathbf{p}^{*}$ \\
\hline \multicolumn{4}{|l|}{ Asuhan Keperawatan, n (\%) } \\
\hline Kurang & $56(84,8)$ & $56(49,1)$ & 0,00 \\
\hline Baik & $10(15,2)$ & $58(50,9)$ & \\
\hline \multicolumn{4}{|l|}{ Pengkajian, n (\%) } \\
\hline Kurang & $55(83,3)$ & $40(35,1)$ & 0,00 \\
\hline Baik & $11(16,7)$ & $74(64,9)$ & \\
\hline \multicolumn{4}{|l|}{ Pengkajian Lanjutan, n (\%) } \\
\hline Kurang & - & - & - \\
\hline Baik & $66(100)$ & $114(100)$ & \\
\hline \multicolumn{4}{|l|}{ Penegakan Diagnosis, n (\%) } \\
\hline Kurang & $18(27,3)$ & $30(26,3)$ & 0,889 \\
\hline Baik & $48(72,7)$ & $84(73,7)$ & \\
\hline \multicolumn{4}{|l|}{ Perumusan Tujuan, n (\%) } \\
\hline Kurang & $16(24,2)$ & $30(26,3)$ & 0,759 \\
\hline Baik & $50(75,8)$ & $84(73,7)$ & \\
\hline \multicolumn{4}{|l|}{ Penyusunan Intervensi, n (\%) } \\
\hline Kurang & $16(24,2)$ & $23(20,2)$ & 0,523 \\
\hline Baik & $50(75,8)$ & $91(79,8)$ & \\
\hline \multicolumn{4}{|l|}{ Implementasi, n (\%) } \\
\hline Kurang & - & - & - \\
\hline Baik & $66(100)$ & $114(100)$ & \\
\hline \multicolumn{4}{|l|}{ Evaluasi Formatif, n (\%) } \\
\hline Kurang & - & - & - \\
\hline Baik & $66(100)$ & $114(100)$ & \\
\hline \multicolumn{4}{|l|}{ Evaluasi Sumatif, n (\%) } \\
\hline Kurang & - & - & - \\
\hline Baik & $66(100)$ & $114(100)$ & \\
\hline
\end{tabular}

${ }^{\star}$ Uji Pearson Chi Square
100\%. Uji beda tidak dapat dilaksanakan oleh karena data tidak bervariasi.

\section{PEMBAHASAN}

Pada penelitian ini, terdapat peningkatan proporsi mutu asuhan keperawatan yang baik secara signifikan sesudah penerapan clinical pathway, hal ini dimungkinkan oleh karena didalam clinical pathway terdapat acuan yang bersifat rekomendatif dalam melaksanakan asuhan keperawatan hariperhari. Clinical pathway memberikan panduan dalam melaksanakan pengkajian awal dan lanjutan, merekomendasikan beberapa diagnosis keperawatan yang sering ditemukan pada pasien dengan penyakit tertentu, merekomendasikan rumusan tujuan dan intervensi yang dapat digunakan dalam merawat pasien serta panduan dalam implementasi dan evaluasi.

Perawat dalam memberikan asuhan keperawatan kepada beberapa pasien, dimungkinkan adanya respon pasien yang berbeda terhadap masalah kesehatan yang dihadapi, didalam situasi ini perawat dapat melakukan pengkajian tambahan sesuai dengan perkembangan respon pasien yang unik dan bersifat individual tersebut, menegakkan diagnosis keperawatan beserta menyusun rencana yang berbeda dengan yang direkomendasikan dalam clinical pathway dengan cara mendokumentasikan didalam rekam medis, kondisi maupun respon pasien serta alasan-alasan yang berbasis keilmuan yang mendasari perbedaan pilihan tersebut yang disebut dengan varian yang relevan. Penulisan alasan yang rasional dan berdasarkan keilmuan direkam medis tersebut yang menjadi kunci penetapan mutu asuhan keperawatan yang baik meskipun memiliki perbedaan dengan rekomendasi dalam clinical pathway, serta penulisan alasan tersebut menjadi payung hukum bagi profesional pemberi asuhan terhadap kemungkinan adanya gugatan hukum dari asuhan yang diberikan kepada pasien.

Penerapan clinical pathway di Rumah Sakit Umum Pusat Sanglah secara proporsi belum secara keseluruhan dapat meningkatkan mutu asuhan keperawatan, hal ini dapat disebabkan oleh karena kurangnya pemahaman dan perhatian perawat dalam menerapkan asuhan keperawatan berbasis bukti dan kelimuan terkini yang sudah disusun dalam bentuk rekomendasi didalam panduan asuhan keperawatan dan clinical pathway sehingga dibutuhkan adanya pelatihan dan sosialisasi penerapan clinical pathway serta peningkatan kompetensi tenaga keperawatan. Kurang optimalnya penerapan clinical pathway dalam peningkatan mutu asuhan keperawatan juga dapat disebabkan oleh karena masih kurangnya dukungan manajemen dalam 
pelaksanaan monitoring dan supervisi. Hasil penelitian ini memperkuat hasil penelitian lain yang menunjukkan hasil bahwa penerapan clinical pathway meningkatkan kualitas pelayanan kesehatan dan mengurangi variasi dalam perawatan klinis. ${ }^{12-14}$

Penerapan clinical pathway sebagai acuan dalam melaksanakan pengkajian keperawatan rawat inap di Rumah Sakit Umum Pusat Sanglah belum secara maksimal dapat meningkatkan mutu pengkajian keperawatan, hal ini dapat disebabkan oleh karena pelaksanaan pengkajian keperawatan membutuhkan waktu yang cukup lama, beban kerja yang tinggi, penggunaan form pengkajian berbasis kertas yang kurang jelas dan kurang komprehensif dan kurangnya pelatihan tentang proses asuhan keperawatan. Mutu pengkajian keperawatan lanjutan sebelum dan sesudah penerapan clinical pathway memiliki mutu yang baik, hal ini dapat disebabkan oleh karena pengkajian keperawatan lanjutan dilaksanakan pada saat serah terima jaga dan adanya perubahan kondisi pasien, dimana kondisi ini dilaksanakan setiap jadwal jaga serta informasi yang dituliskan dalam pengkajian lanjutan merupakan materi yang diserah terimakan pada saat pergantian jaga sehingga tenaga keperawatan menjadi terbiasa dalam pelaksanaannya.

Penerapan clinical pathway tidak secara bermakna meningkatkan mutu penegakan diagnosis keperawatan, dimana terdapat peningkatan proporsi mutu penegakan diagnosis keperawatan yang baik sesudah penerapan clinical pathway sebesar $1 \%$. Hasil penelitian ini dapat disebabkan oleh karena penegakan diagnosis keperawatan mengacu kepada situasi klinis pasien dalam merespon masalah kesehatan baik nyata maupun potensial yang unik dan bersifat individual (Tim Pokja SDKI DPP PPNI, 2017), sehingga memungkinkan adanya penegakan diagnosis keperawatan yang bervariasi dalam satu jenis diagnosis medis. Penyebab lainnya adalah penerapan clinical pathway yang bersifat rekomendasi dan dikembangkan untuk pasien dalam kondisi rata-rata atau lazim sehingga tidak sesuai untuk diterapkan untuk seluruh pasien. ${ }^{15}$ Dalam penilaian mutu, penegakan diagnosis keperawatan yang berbeda dengan clinical pathway, dimungkinkan dalam praktik keperawatan dengan menuliskan alasan rasional yang menjadi dasar penegakan diagnosis keperawatan yang berbeda tersebut di dalam rekam medis.

Hasil penelitian ini juga dapat disebabkan oleh karena kurangnya pelatihan tentang penerapan clinical pathway yang dapat meningkatkan pengetahuan dan kemampuan tenaga keperawatan untuk berpikir kritis, belum diterapkannya penggunaan bahasa keperawatan yang terstandar, kurangnya supervisi dari manajemen dan belum diterapkannya rekam medis elektronik secara penuh.
Mutu rencana keperawatan terdiri dari mutu perumusan tujuan dan mutu penentuan intervensi keperawatan. Hasil penelitian ini menunjukkan adanya penurunan proporsi mutu perumusan tujuan keperawatan yang baik sesudah penerapan clinical pathway sebesar 2,1\%, hal ini disebabkan oleh karena penentuan tujuan asuhan keperawatan merupakan pernyataan yang menggambarkan perubahan-perubahan yang diinginkan pada kondisi atau perilaku pasien yang bersifat dinamis sehingga dapat berubah dengan cepat (Moorhead, et al., 2016). Variasi dalam perumusan tujuan asuhan keperawatan yang tidak sesuai dengan clinical pathway, dapat disebabkan oleh karena dalam perumusannya harus mempertimbangkan karakteristik pasien yang unik, ketersediaan sumber daya, dipengaruhi oleh persepsi dan harapan pasien tentang status kesehatannya serta potensi pengobatan yang berbeda-beda. ${ }^{16}$ Ketidaksesuaian perumusan tujuan asuhan keperawatan hendaknya ditulis dalam rekam medis dengan menyertakan dasar-dasar pertimbangan yang logis dalam perumusan tujuan sehingga mutu perumusan tujuan menjadi baik. Pendokumentasian dasar pertimbangan ini belum dilaksanakan secara menyeluruh didalam rekam medis dapat disebabkan oleh kurangnya sosialisasi atau pelatihan terkait penerapan clinical pathway. Selain hal tersebut diatas hasil penelitian ini dapat disebabkan oleh karena belum menggunakan rekam medis elektronik, serta kurangnya dukungan manajemen berupa supervisi, dan pembinaan. Hasil penelitian ini sesuai dengan penelitian yang dilaksanakan di Ontario, Kanada dimana disimpulkan terdapat tujuh hambatan dalam penerapan clinical pathway yang terdiri dari pemahaman dan standarisasi penerapan clinical pathway yang kurang, kondisi spesifik pasien, kompetensi profesional pemberi asuhan yang kurang, dinamika tim profesional pemberi asuhan yang kurang mendukung, strategi penerapan berupa penyusunan regulasi dan dukungan manajemen rumah sakit yang belum optimal serta belum optimalnya upaya peningkatan mutu layanan kesehatan berkesinambungan. ${ }^{17}$

Penelitian ini memberikan informasi bahwa penerapan clinical pathway di Rumah Sakit Umum Pusat Sanglah Denpasar tidak dapat meningkatkan mutu penentuan intervensi keperawatan secara signifikan, meskipun secara proprosi terdapat peningkatan proporsi mutu penentuan intervensi keperawatan yang baik sesudah penerapan clinical pathway sebesar 4\%. Penentuan intervensi keperawatan yang tidak sesuai dengan clinical pathway disebabkan oleh karena dalam penentuan intervensi keperawatan terdapat variasi dalam penilaian klinis dengan mempertimbangkan hasil yang diharapkan pasien, pilihan intervensi yang 
mungkin dilaksanakan dan penerimaan pasien sehingga penentuan intervensi keperawatan untuk satu orang pasien dengan jenis diagnosis medis yang sama, dapat berbeda dengan pasien yang lain. ${ }^{18}$ Penyebab lain yang adanya dalam praktik klinis adalah adanya keterbatasan kompetensi dari tenaga keperawatan, keterbatasan sumber daya yang tersedia dan belum diterapkannya bahasa keperawatan terstandar.

Penyesuaian penentuan intervensi keperawatan dalam melaksanakan asuhan kepada pasien yang unik merupakan hal yang sangat penting dalam menjaga mutu asuhan keperawatan, dasar pertimbangan dalam penentuan intervensi yang berbasis bukti dan rasional tersebut perlu ditulis sebagai wawanti atau penyangkalan dalam rekam medis sehingga dasar pertimbangan perawat penanggung jawab pasien tidak mengikuti standar intervensi keperawatan dalam clinical pathway dapat dipahami oleh profesional pemberi asuhan lainnya yang menggunakan rekam medis tersebut. Penulisan wawanti ini tidak penulis temukan dalam sampel rekam medis yang dianalisis dalam penelitian ini, sehingga dapat disimpulkan kurangnya pemahaman profesional pemberi asuhan dan standarisasi penerapan clinical pathway di Rumah Sakit Umum Pusat Sanglah juga sebagai penyebab mutu penentuan intervensi keperawatan kurang optimal selain belum diterapkannya rekam medis elektronik secara penuh.

Hasil penelitian ini menyajikan informasi tidak adanya perbedaan mutu implementasi keperawatan sebelum dan sesudah penerapan clinical pathway. Mutu implementasi keperawatan yang baik tersebut disebabkan oleh karena dalam tahapan implementasi keperawatan, tenaga keperawatan melaksanakan beberapa aktivitas sesuai dengan rencana keperawatan yang sudah ditetapkan dan sudah terdokumentasi dalam rekam medis pasien. Implementasi keperawatan terdiri dari perawatan langsung yang merupakan interaksi langsung dengan pasien dan perawatan tidak langsung yang merupakan bentuk penatalaksanaan tanpa berinteraksi dengan pasien namun terkait dengan upaya memperbaiki status kesehatan pasien yang dalam pelaksanaannya disesuaikan dengan respon pasien.

Penelitian ini menyajikan informasi mutu evaluasi formatif dan sumatif keperawatan yang baik sebelum dan sesudah penerapan clinical pathway. Hasil penelitian ini merupakan gambaran pelaksanaan kegiatan yang sistematis, berkesinambungan serta terencana untuk membandingkan kondisi kesehatan pasien dengan target hasil perawatan yang telah ditetapkan dalam tujuan keperawatan. Hasil penilaian berupa evaluasi formatif didasarkan pada penilaian terhadap respon pasien segera setelah diberikan intervensi keperawatan yang dicatat dalam formulir yang sama dengan catatan implementasi keperawatan sehingga memudahkan dalam pelaksanaannya.

Evaluasi sumatif keperawatan yang merupakan kesimpulan dari hasil penilaian pencapaian tujuan asuhan keperawatan sesuai waktu yang ditetapkan dalam tujuan keperawatan, ditulis dalam catatan perkembangan pasien yang disampaikan pada saat serah terima jaga keperawatan sehingga menjadi kebiasaan dalam pelaksanaannya.

\section{SIMPULAN}

Hasil penelitian ini menunjukkan bahwa mutu asuhan dan pengkajian keperawatan sesudah penerapan clinical pathway lebih baik daripada mutu asuhan keperawatan sebelum penerapan clinical pathway. Akan tetapi tidak terdapat perbedaan mutu penegakan diagnosis keperawatan, rencana keperawatan, mutu implementasi keperawatan, dan evaluasi keperawatan sebelum maupun sesudah penerapan clinical pathway.

\section{KONFLIK KEPENTINGAN}

Tidak terdapat konflik kepentingan dalam penulisan laporan penelitian ini.

\section{PERSETUJUAN ETIK}

Penelitian ini telah mendapat persetujuan etik dari Komisi Etik Fakultas Kedokteran Universitas Udayana, Bali, Indonesia sebelum penelitian berjalan.

\section{PENDANAAN}

Penulis bertanggung jawab terhadap pendanaan penelitian ini tanpa melibatkan pihak sponsor, beasiswa, atau sumber pendanaan lainnya.

\section{KONTRIBUSI PENULIS}

Seluruh penulis memiliki kontribusi yang sama dalam penulisan laporan penelitian ini baik dari tahap penyusunan kerangka konsep penelitian, pengambilan data, analisis data, hingga interpretasi data penelitian yang dipublikasikan pada penelitian ini.

\section{DAFTAR PUSTAKA}

1. Bosse G, Ngoli B, Leshabari MT, Kulker R, Dammrich T, Abels W, et al. Quality of health care and the need for assessment. East Afr J Public Health. 2011;8(3):199-204.

2. Mosadeghrad AM. Healthcare service quality: towards a broad definition. Int J Health Care Qual Assur. 2013;26(3):203-219. 
3. World Health Organization. Delivering Quality Health Services A Global Imperative for Universal Health Coverage. Switzerland: WHO Publication. 2018;1-93.

4. Arcaya MC, Arcaya AL, Subramanian SV. Inequalities in health: definitions, concepts, and theories. Glob Health Action. 2015;8:27106.

5. Cheah J. Development and implementation of a clinical pathway programme in an acute care general hospital in Singapore. Int J Qual Health Care. 2000;12(5):403-412.

6. Hipp R, Abel E, Weber RJ. A Primer on Clinical Pathways. Hosp Pharm. 2016;51(5):416-421. doi:10.1310/ hpi5105-416.

7. Cheah TS. Clinical pathways--the new paradigm in healthcare?. Med J Malaysia. 1998;53(1):87-96.

8. Asmirajanti M, Syuhaimie Hamid AY, Hariyati TS. Clinical care pathway strenghens interprofessional collaboration and quality of health service: a literature review. Enferm Clin. 2018;28 Suppl 1:240-244.

9. Komite Medik RSUP Sanglah. Panduan Integrated Clinical Pathway. Denpasar. 2017.

10. Direktur Utama RSUP Sanglah. Surat Keputusan Direktur Utama RSUP Sanglah Denpasar tentang Lima Area klinis Prioritas. Denpasar. 2018.

11. Komite Medik RSUP Sanglah. Laporan Pemantauan Clinical Pathway Komite Medik RSUP Sanglah. Denpasar. 2018.

12. Bao H, Yang F, Su S, Wang X, Zhang M, Xiao Y, et al. Evaluating the effect of clinical care pathways on quality of cancer care: analysis of breast, colon and rectal cancer pathways. J Cancer Res Clin Oncol. 2016;142(5):1079-1089.
13. Lawal AK, Rotter T, Kinsman L, Machotta A, Ronellenfitsch U, Scott DS, et al. What is a clinical pathway? Refinement of an operational definition to identify clinical pathway studies for a Cochrane systematic review. BMC Med. 2016;14:35.

14. Maryam Y, Sima R, Omid K, Elmira M, Mina J, Samaneh S, et al. A systematic review of factors influencing healthcare services marketing in Iran. Bali Medical Journal. 2017;6(2):268-278.

15. Tim Pokja SDKI DPP PPNI. Standar Diagnosis Keperawatan Indonesia. 1 ed. Jakarta: Dewan Pengurus Pusat Persatuan Perawat Nasional Indonesia. 2017.

16. Moorhead S. Johnson M, Maas M, Swanson E. Nursing Outcomes Classification. Edisi Kelima. Disunting oleh I. Nurjannah dan R. De. Tumanggor. CV. Mokomedia. 2016:1-776.

17. Jabbour M, Newton AS, Johnson D, Curran JA. Defining barriers and enablers for clinical pathway implementation in complex clinical settings. Implement Sci. 2018;13(1):139.

18. Bulechek GM, McCloskey JC. Nursing interventions classification (NIC). Medinfo. 1995;8 Pt 2:1368.

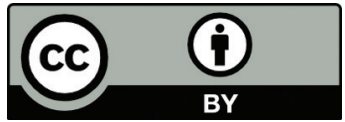

This work is licensed under a Creative Commons Attribution 